\title{
Surgical options for nonparasitic splenic cysts in children - Is splenectomy always necessary?
}

\author{
Kailas P Bhandarkar ${ }^{1,2 *}$, Santosh V Patil ${ }^{2}$, Dinesh H Kittur ${ }^{2}$ and Sudhakar S Jadhav ${ }^{2}$ \\ ${ }^{1}$ Department of Paediatric Surgery, Evelina London Children's Hospital, London, UK \\ ${ }^{2}$ Department of Paediatric Surgery, Sushrut Jadhav Kinderchirurgie Charitable Trust's Paediatric Surgery Centre and PG Institute, India
}

\begin{abstract}
Aims: To study the different options of surgical management of nonparasitic splenic cysts in children.

Materials and methods: This is a study of six children with nonparasitic cysts of spleen. All were operated over last five years. All children were symptomatic and underwent surgery. Various surgical procedures were performed. These were classified based on possibility of splenic conservation. Four children underwent splenic conservation procedures and two children underwent splenectomy. Various splenic conservation procedures are discussed.
\end{abstract}

Results: There were no long-term complications or recurrences in four patients in the splenic conservation group.

Conclusion: Nonparasitic splenic cysts are best managed by splenic conservation surgery whenever feasible. Splenectomy is rarely necessary.

\section{Introduction}

Splenic cysts are a rare in children. Clinically, they may be asymptomatic or symptomatic. Symptomatic patients usually present with abdominal pain or rarely abdominal lump. Small asymptomatic splenic cysts which are less than 5 centimetres can be conserved. In the past, splenectomy was the treatment of choice for these cysts. Presently, surgery is aimed at splenic conservation techniques. These procedures could be performed either by open or by minimal access techniques.

\section{Methods}

This is a retrospective study of six patients who were referred with the diagnosis of splenic cysts. All patients were worked up with an ultrasound and a contrast enhanced CT scan of the abdomen to look for the size and location of the splenic cysts. After surgery they were followed up in the out-patient clinic with a clinical examination and an ultrasound of the abdomen. Those who underwent a splenectomy received pneumcoccal and haemophilus influenzae $B$ vaccine at follow-up.

\section{Results}

Total of six patients were included in our study. Patient characteristics are summarised in table 1 . The mean age was 10 years (range $8-15$ years). There were five males (83\%) and one female (17\%). All patients were symptomatic and presented with varying duration of abdominal pain ranging from two weeks to one year. The only other symptom was the presence of an abdominal lump. Clinical examination revealed splenomegaly at presentation in two patients (patient 1 and 4). CT scan revealed moderate sized splenic cysts measuring more than 5 centimetres in two patients (patient 1 and 6). All other patients had huge splenic cysts replacing almost whole of the splenic parenchyma.

Four patients underwent splenic conservation surgery. These included deroofing, marsupialisation with omental pedicle and cyst excision. Patient 1 and 4 underwent cyst excision and splenorrhaphy (Figure 1) since the cyst could easily be separated from the splenic parenchyma. Patient 3 had a huge splenic cyst which could not be separated from the splenic parenchyma and therefore underwent marsupialisation and placement of an omental pedicle. Patient number 6 had a cyst abutting the surface of the spleen (CT scan picture, Figure 2) which was amenable to deroofing (operative picture, Figure 3 ).

Two patients underwent splenectomy. Patient 2 had a large cyst occupying whole of the spleen with hardly any residual splenic parenchyma around the cyst (CT scan picture, Figure 4). This patient therefore underwent splenectomy. Patient number 5 had an infected cyst with dense perisplenic adhesions. Difficult dissection coupled with bleeding near the splenic hilum during surgery necessitated a splenectomy. We did not perform any minimal access surgery for any of these cysts. Regular out-patient follow-up did not reveal any residual or recurrent cyst except in patient 3. This cyst was noted in this patient one month after surgery and was in much smaller dimensions. He was asymptomatic and so was followed up regularly with ultrasound. The cyst regressed without any active intervention. All patients continue to follow-up regularly in the outpatient department. Histopathological examination of the splenic cysts revealed epithelial cyst in three patients and pseudocysts in the rest. We did not use any immuno-histochemical stains for histopathological examination.

${ }^{\star}$ Correspondence to: Kailas P Bhandarkar, Department of Paediatric Surgery, Evelina London Children's Hospital, London, UK, E-mail: drbhandarkar@ hotmail.com

Key words: Splenic conservation, cyst excision, marsupialisation, partial splenectomy, splenectomy

Received: August 28, 2018; Accepted: September 24, 2018; Published: September 28, 2018 
Bhandarkar KP (2018) Surgical options for nonparasitic splenic cysts in children - Is splenectomy always necessary?

Table 1. Patient characteristics

\begin{tabular}{|l|l|l|l|l|l|}
\hline Sl. no. & Age (Y) & Sex & Clinical features & Surgical procedure & Histology \\
\hline 1 & 8 & M & $\begin{array}{l}\text { Abdominal pain since 1 month } \\
\text { splenomegaly }\end{array}$ & Cyst excision and splenorraphy & Pseudocyst \\
\hline 2 & 12 & M & Abdominal pain since 1 year & splenectomy & Epithelial cyst \\
\hline 3 & 15 & M & Abdominal pain since 1 year & $\begin{array}{l}\text { Marsupialisation } \\
\text { and omental pedicle }\end{array}$ & Epithelial cyst \\
\hline 4 & 9 & F & $\begin{array}{l}\text { Abdominal pain and abdominal } \\
\text { lump since 2 weeks } \\
\text { splenomegaly }\end{array}$ & Cyst excision & Pseudocyst \\
\hline 5 & 12 & M & Abdominal pain since 1 year & Splenectomy & None,2 y \\
\hline 6 & 15 & M & Abdominal pain since 6 months & Deroofing of cyst wall & Pseudocyst \\
\hline
\end{tabular}

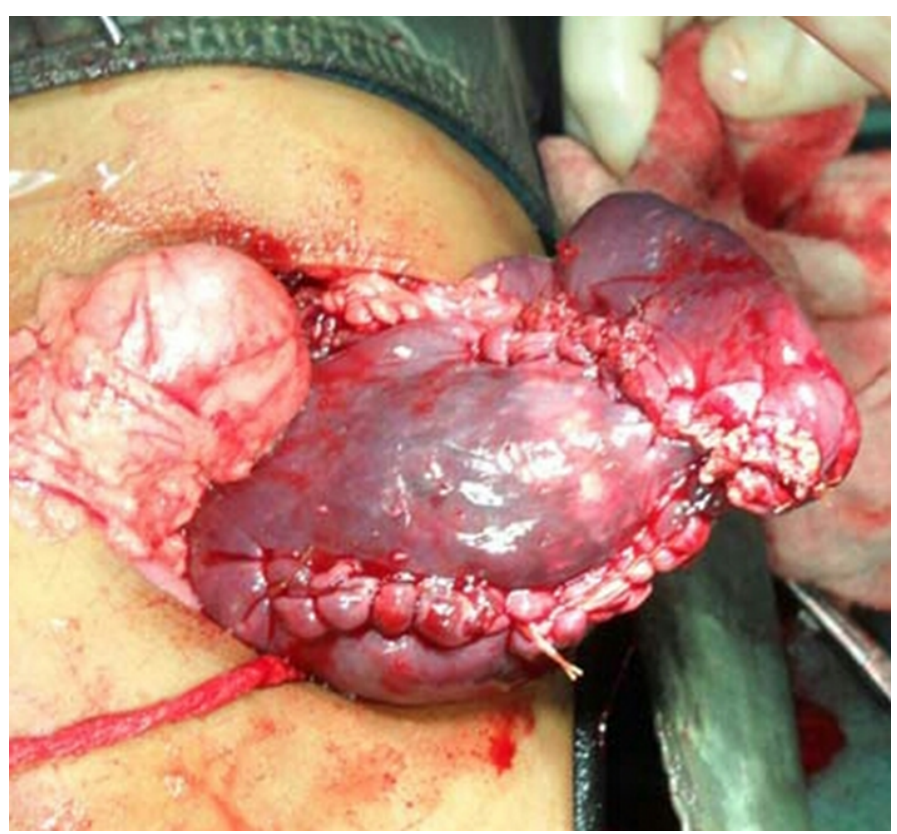

Figure 1. Cyst excision and splenorraphy

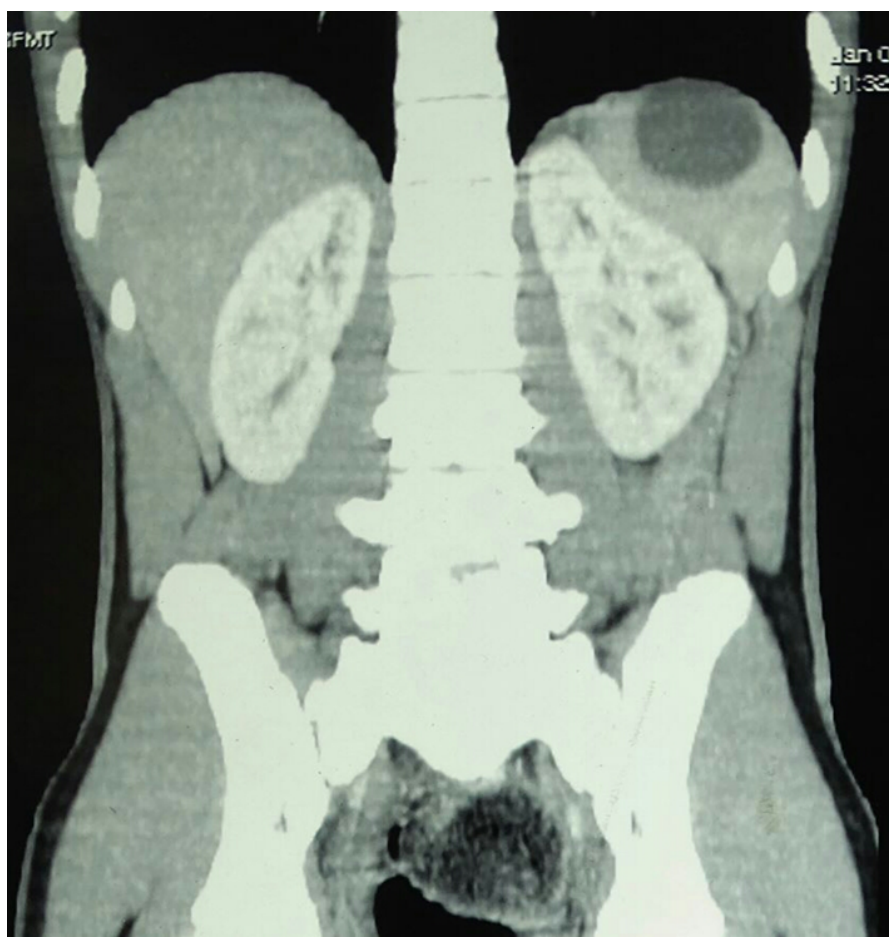

Figure 2. CT Scan shows splenic cyst abutting the surface of the spleen 


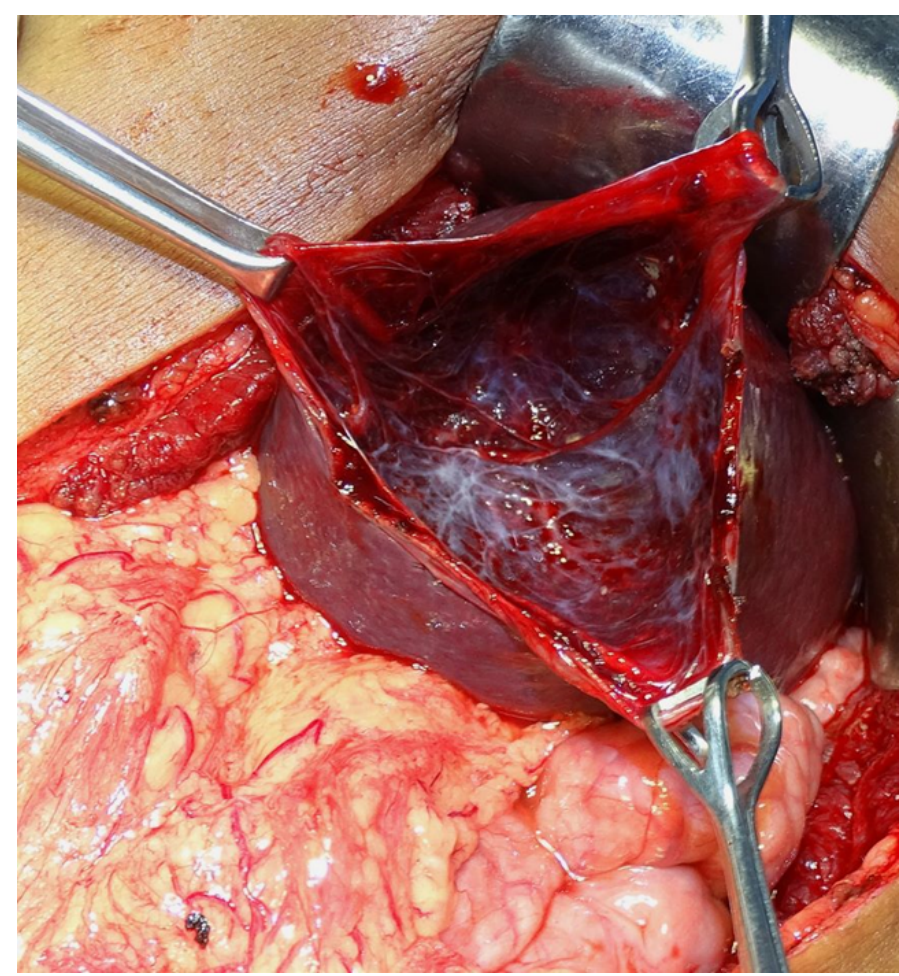

Figure 3. Deroofing of splenic cyst shown in figure 2

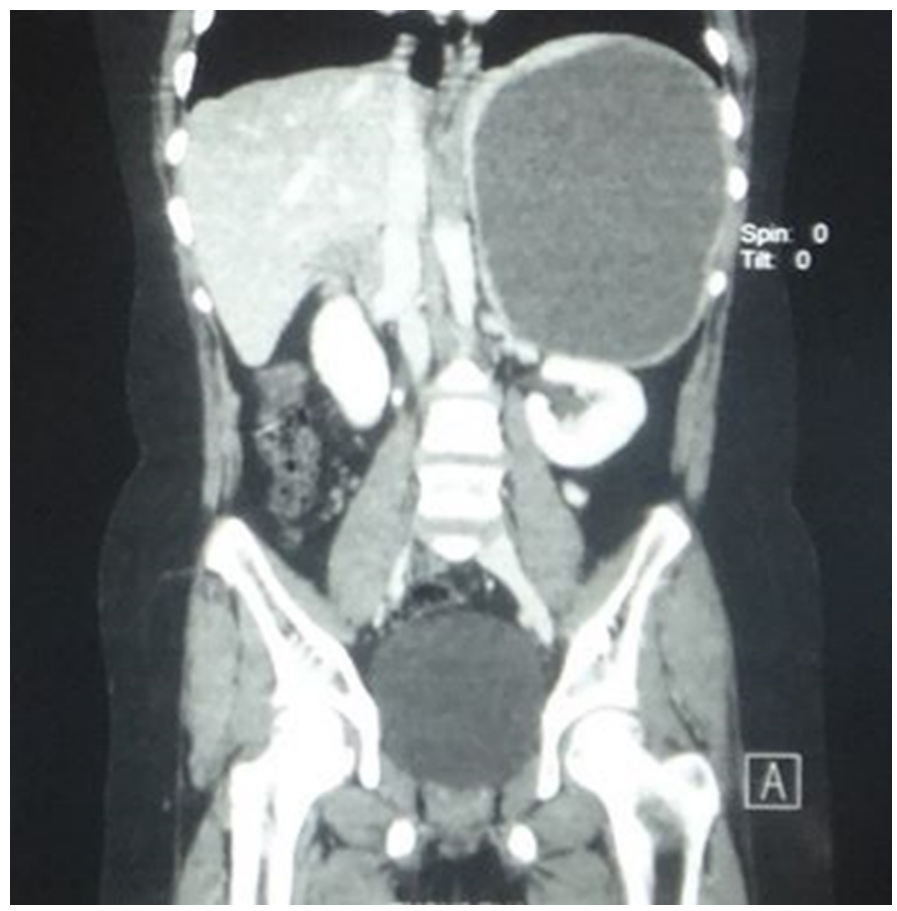

Figure 4. CT scan shows a large splenic cyst replacing almost whole of the spleen

\section{Discussion}

Splenic cysts are rare with an incidence of $0.07 \%$. The classification of splenic cysts was first attempted by Fowler [1]. He classified nonparasitic cysts as true cysts or primary cysts and false or pseudo cysts based on the presence or absence of an epithelial lining. The current classification is by Mirilas P et al. [2], who classified splenic cysts into primary splenic cysts (includes congenital and neoplastic cysts) and secondary cysts (consisting of traumatic and necrotic cysts. True cysts are also called congenital cysts and are defined by the presence of an inner endothelial lining [3]. They are developmental in origin and the lining is formed secondary to an infolding of peritoneal mesothelium or collection of mesothelial cells trapped within splenic sulci [4,5]. True cysts can sometimes be classified wrongly as pseudocysts when the cyst lining has been destroyed, for example by an infection. Palmieri I et al. [6] have established the pathological diagnosis of congenital cysts by immunohistochemistry using cytokeratin, CEA, CA19-9, and Calretinin.

Primary cysts comprise about $30-40 \%$ of splenic cysts and are more common in children than in adults [7]. Most cysts are asymptomatic. The usual clinical presentation of symptomatic splenic cysts includes left upper abdominal pain or discomfort often accompanied by feeling of fullness. Infected cysts can present with fever, vomiting or a raised leukocyte count.

Splenomegaly is usually present when the cyst is more than $6 \mathrm{~cm}$ in size [6]. Splenic cysts larger than $5 \mathrm{~cm}$ are more prone to complications like haemorrhage, rupture or infection and surgical treatment is therefore recommended [7]. In our series, all patients were symptomatic for varying duration ranging from two weeks to one year.

Two of them had splenomegaly at presentation. Though we had one patient with an infected splenic cyst, he had no history of fever. Laparotomy with splenectomy has been the treatment of choice for congenital splenic cysts in the past. However splenic conservation is currently practiced to avoid OPSI (overwhelming post splenectomy infection) in children [8]. Recent advances including technical improvements in imaging and operative surgery coupled with appreciation of segmental anatomy of the spleen as led to practice of splenic conservation [9]. These techniques have evolved since Morgenstern and Shapiro first performed partial splenectomy for splenic cyst [10]. Splenic preservation techniques include decapsulation, deroofing, marsupialisation, cyst excision and partial splenectomy with or without placement of an omental pedicle. Any or all of these procedures can be performed either by laparoscopic or open methods $[7,11]$.

Technical details during splenic conservation includes ligation of polar vessels, splenic division, buttressing sutures and omental pedicle [12]. Decapsulation involves a near total excision of the cyst and leaving a portion of the cyst wall contiguous with splenic parenchyma. Advantages include less blood loss and speed of operation. Recurrence appears to be low [13].

Currently, all splenic conservation procedures can be performed laparoscopically with several advantages [14]. Some studies, however, have noted higher recurrence rates after laparoscopic deroofing or decapsulation of splenic cysts (64\%) [15]. Other studies did not report any long-term recurrences or complications and advocate laparoscopic splenic conservation $[13,16]$. Splenectomy is performed only if the cyst is occupying the hilum making dissection difficult or if the cyst is large replacing nearly all of the splenic parenchyma [17].

A recent review of 166 patients with splenic cysts by Sinha et al showed that most cysts were congenital (82\%), and $47 \%$ were diagnosed incidentally. Laparotomy was performed for two thirds of the patients and rest were treated laparoscopically. Splenectomy rate was higher in the open group as compared to the minimally invasive group. Interestingly recurrence was low in the open group compared to the minimal invasive group. This study also reported treatment of asymptomatic cysts measuring less than 5 centimetres conservatively with regular follow up by ultrasound [18]. 
In our own series of six patients, two (33\%) underwent splenectomy for the reasons already mentioned. We did not have any long-term recurrences in the splenic conservation group at follow up. Based on size of the cysts and location of cysts in the spleen we feel that small asymptomatic cysts less than 5 centimetres can be followed up with safely with regular ultrasound examination. This has been also echoed by other researchers [19].

Symptomatic cysts should always be treated surgically. Cysts involving only a part of the spleen projecting to the surface can be easily dealt with by marsupialisation, deroofing, or cyst excision. Deep seated cysts not accessible to the above procedures are best treated with partial splenectomy and splenorrhaphy. Partial splenectomy may also be performed laparoscopically [20]. Cysts involving almost whole of the spleen, presence of dense perisplenic adhesions, grossly infected cyst or hilar location warrant a splenectomy.

Lastly, splenic autotransplantation must be always be attempted whenever a splenectomy is carried out. Most common techniques for splenic auto transplantation include implantation in the omental pouch [21]. There are reports that suggest significant antibody response to pneumococcal antigens after splenic auto transplantation. This could contribute to overall protection against OPSI [22].

\section{Conclusion}

Splenic cysts are rare entity in children. Uncomplicated and asymptomatic small cysts can be managed conservatively with regular follow up. Symptomatic cysts always require surgery. They are best managed by open or laparoscopic splenic conservation techniques whenever feasible. Splenectomy should only be reserved as a last resort.

\section{Acknowledgement}

The authors would like to thank Dr. Yogesh Tiwari and Aamir Iqbal (residents) and Mr. Mohsin Mujawar for technical assistance in preparing the manuscript.

\section{References}

1. Fowler RH (1953) Nonparasitic benign cystic tumors of the spleen. Int Abstr Surg 96: 209-227. [Crossref]

2. Mirilas P, Mentessidou A, Skandalakis JE (2007) Splenic cysts: are there so many types? J Am Coll Surg 204: 459-465. [Crossref]

3. Kawashima A, Fishman E. (1994) Benign splenic lesions. In, Gore RM, Levine MS, Laufer I (Eds). Textbook of Gastrointestinal Radiology. Philadelphia, Saunders: 22512299.

4. Freeman JL, Jafri SZ, Roberts JL, Mezwa DG, Shirkhoda A (1993) CT of congenital and acquired abnormalities of the spleen. Radiographics 13: 597-610. [Crossref]
5. Ough YD, Nash HR, Wood DA (1981) Mesothelial cysts of the spleen with squamous metaplasia. Am J Clin Pathol 76: 666-669. [Crossref]

6. Palmieri I, Natale E, Crafa F, Cavallaro A, Mingazzini PL (2005) Epithelial splenic cysts. Anticancer Res 25: 515-521. [Crossref]

7. Morgenstern L (2002) Nonparasitic splenic cysts: pathogenesis, classification, and treatment. J Am Coll Surg 194: 306-14. [Crossref]

8. Smith ST, Scott DJ, Burdick JS, Rege RV, Jones DB (2001) Laparoscopic marsupialization and hemisplenectomy for splenic cysts. J Laparoendosc Adv Surg Tech A 11: 243-9. [Crossref]

9. Redmond HP, Redmond JM, Rooney BP, Duignan JP, Bouchier-Hayes DJ (1989) Surgical anatomy of the human spleen. Br J Surg 76: 198-201. [Crossref]

10. Morgenstern L, Shapiro SJ (1980) Partial splenectomy for nonparasitic splenic cysts. Am J Surg 139: 278-281. [Crossref]

11. Hansen MB, Moller AC (2004) Splenic cysts. Surg Laparosc Endosc Percutan Tech 14: 316-322. [Crossref]

12. Williams RJ, Glazer G (1993) Splenic cysts: changes in diagnosis, treatment and aetiological concepts. Ann R Coll Surg Engl 75: 87-89. [Crossref]

13. Mackenzie RK, Youngson GG, Mahomed AA (2004) Laparoscopic decapsulation of congenital splenic cysts: a step forward in splenic preservation. J Pediatr Surg 39: 8890. [Crossref]

14. Tagaya N, Oda N, Furihata M, Nemoto T, Suzuki N, et al. (2002) Experience with laparoscopic management of solitary symptomatic splenic cysts. Surg Laparosc Endosc Percutan Tech12: 279-82. [Crossref]

15. Schier F, Waag KL, Ure B (2007) Laparoscopic unroofing of splenic cysts results in a high rate of recurrences. J Pediatr Surg 42: 1860-1863. [Crossref]

16. Gianom D, Wildisen A, Hotz T, Goti F, Decurtins M (2003) Open and laparoscopic treatment of nonparasitic splenic cysts. Dig Surg 20: 74-78. [Crossref]

17. Macheras A, Misiakos EP, Liakakos T, Mpistarakis D, Fotiadis C, et al. (2005) Nonparasitic splenic cysts: A report of three cases. World J Gastroenterol 11: 6884-7. [Crossref]

18. Sinha CK, Agrawal M (2011) Nonparasitic splenic cysts in children: Current status. Surgeon 9: 49-53. [Crossref]

19. Gezer HÖ, Oğuzkurt P, Temiz A, İnce E, Ezer SS, et al. (2016) Spleen Salvaging Treatment Approaches in Non-parasitic Splenic Cysts in Childhood. Indian J Surg 78: 293-298. [Crossref]

20. Garza-Serna U, Ovalle-Chao C, Martinez D, Flores-Villalba E, Diaz-Elizondo JA, et al. (2017) Laparoscopic partial splenectomy for congenital splenic cyst in a pediatric patient: Case report and review of literature. Int J Surg Case Rep 33: 44-47. [Crossref]

21. Pisters PW, Pachter HL (1994) Autologous splenic transplantation for splenic trauma. Ann Surg 219: 225-235. [Crossref]

22. Leemans R, Harms G, Rijkers GT, Timens W (1999) Spleen autotransplantation provides restoration of functional splenic lymphoid compartments and improves the humoral immune response to pneumococcal polysaccharide vaccine. Clin Exp Immunol 117: 596-604. [Crossref]

Copyright: (C2018 Bhandarkar KP. This is an open-access article distributed under the terms of the Creative Commons Attribution License, which permits unrestricted use, distribution, and reproduction in any medium, provided the original author and source are credited. 